\title{
Role of nutritional supplements in the management of tendinopathies: focus on combination of type 1 collagen, vitamin $C$ and mucopolysaccharides
}

\author{
Dinesh Agrawal $^{1}$, Aalok Shah ${ }^{2}$, Kapil Dev Mehta ${ }^{3 *}$, Rishi Jain ${ }^{3}$, Salman Motlekar ${ }^{4}$ \\ ${ }^{1}$ Department of Orthopaedics, Raksha Hospital Pvt. Ltd., Ahmedabad, Gujarat, India \\ ${ }^{2}$ Department of Orthopaedics, GCS Medical College, Naroda, Ahmedabad, Gujarat, India \\ ${ }^{3}$ Department of Medical Affairs, Wockhardt Ltd., Bandra Kurla Complex, Mumbai, Maharashtra, India \\ ${ }^{4}$ Department of Medical Information, Wockhardt Ltd., Bandra Kurla Complex, Mumbai, Maharashtra, India
}

Received: 03 June 2020

Revised: 23 July 2020

Accepted: 29 July 2020

\section{*Correspondence:}

Dr. Kapil Dev Mehta,

E-mail: kapilm@wockhardt.com

Copyright: ( ) the author(s), publisher and licensee Medip Academy. This is an open-access article distributed under the terms of the Creative Commons Attribution Non-Commercial License, which permits unrestricted non-commercial use, distribution, and reproduction in any medium, provided the original work is properly cited.

\begin{abstract}
Tendinopathy is a common disease that is difficult to manage due to its recurrent nature. It is associated with increased healthcare costs and significantly impacts quality of life of patients. Also, according to recent studies patients with high cholesterol and diabetes are at a higher risk of developing tendinopathy. There has been rise in the incidence of tendinopathies due to increase in sport activities, life expectancy and some other factors (environment, diet and some drug therapies). Approximately $30 \%$ of visits for musculoskeletal pain in general practice are related to tendon injury. Non-steroidal anti-inflammatory drugs (NSAIDs) and corticosteroids remain the mainstay of treatment. Despite the use of current therapies, there is need of a supportive therapy that can help in the healing process towards development of physiologically normal tendons. Nutraceuticals have been used as supportive therapy for management of tendinopathies. This review focuses on the management of tendinopathy with special attention on role of nutraceuticals such as type I collagen, mucopolysaccharides and vitamin $\mathrm{C}$ in the management of tendinopathy. Clinical data suggests that this combination (type I collagen, mucopolysaccharides and vitamin C) promotes the endogenous synthesis of collagen type I, avoiding the accumulation of collagen type III and aggrecan, thus interfering with the degeneration of tendon tissue. Based on the available clinical data, combination of type I collagen, mucopolysaccharides and vitamin $\mathrm{C}$ not only reduce the clinical symptoms but also improve structural evolution of different types of tendinopathies as well as plantar fascitis.
\end{abstract}

Keywords: Tendinopathy, Nutraceuticals, Type I collagen, Vitamin C, Mucopolysaccharides

\section{INTRODUCTION}

In general practice, tendinopathy is a commonly encountered clinical problem which is not only associated with significant health care costs, but also adversely affects the quality of life of patients. ${ }^{1}$ There is minimal data on the incidence and prevalence of tendon injuries in India, however it has been reported that approximately $30 \%$ of patient visits due to musculoskeletal pain are related to tendon injury. ${ }^{2}$ Three most commonly effected tendons are the Achilles, patellar and rotator cuff tendons. Out of these three, rotator cuff tendons are the most commonly affected followed by Achilles and patellar tendon. ${ }^{3}$ Other frequently injured tendons are around the elbow (golfer's and tennis elbow) and around the wrist. In recent years, increase in sport activities, life expectancy and factors such as environment, diet, systemic diseases and certain drug therapies have led to an exponential increase in the 
incidence of tendinopathies. Moreover, a study by Tilly et al highlighted the role of increased serum cholesterol and diabetes in predisposing the patients towards significantly higher risk of developing tendinopathy. ${ }^{4}$

The main treatment of tendinopathy includes eccentric exercises, pain management and recurrence prevention. Analgesic and anti-inflammatory drugs like non-steroidal anti-inflammatory drugs (NSAIDs) and corticosteroid injections are the gold standard tendinopathy management option. Other widely used therapies in the management of tendinopathy include injections of platelet-rich plasma (PRP) or autologous blood. Surgical intervention is usually recommended if the results of medical management are unsatisfactory. Despite the use of currently available treatment options, tendon structure and mechanical properties after injury usually do not resemble to that of healthy tendons. This can result in disability that lasts for several months and ultimately lead to weaker tendon that is susceptible to further injury. ${ }^{5}$ Consequently, there remains a need for therapeutics that can direct the healing process toward the development of physiologically normal tendons.

The primary purpose of this review is to summarize the treatment options available for the management of tendinopathy and the role of nutraceuticals like type I collagen, mucopolysaccharides and vitamin $\mathrm{C}$ in the management of tendinopathy.

\section{Normal tendon}

Healthy tendons are brilliant white in colour and have a fibroelastic nature. The normal function of tendon consists of transmitting force from muscle to bone and act as a buffer by absorbing external forces to limit muscle damage. ${ }^{6}$ They also show high mechanical strength, good flexibility and an optimal level of elasticity. ${ }^{7}$ The structure of tendon can be divided in two parts: a cellular part, and an extracellular matrix. The cellular part consists of tenoblasts, tenocytes, chondrocytes, synovial cells (outer sheath), capillary endothelial cells and arteriolar smooth muscle cells. Tenoblasts and tenocytes constitute $90 \%$ of the cells of tendon. Tenoblasts are immature tendon cells which on maturation, take on a more elongated shape and become tenocytes. ${ }^{8}$ Their main function is to produce extracellular matrix (ECM) such as collagen, fibronectin and proteoglycans, to maintain tendon homeostasis and repair injured tendons.

\section{PATHOPHYSIOLOGY OF TENDON INJURY AND HEALING}

While, tendonitis is characterized by inflammation, tendinosis involves the degenerative changes in the tendon structure particularly the collagen. Tendon healing is generally a very slow and incomplete process and with advancing age, the metabolic pathways within tendons tend to shift from aerobic to anaerobic energy production. ${ }^{9}$

${ }^{11}$ As compared to the skeletal muscles, the tendons and ligaments have 7.5 times lower oxygen consumption, which leads to lower metabolic rate and subsequent slow healing after tendon injury. ${ }^{12}$ Tendinosis occurs due to failure of the cell matrix to adapt to a variety of stress and trauma as a result of the imbalance between matrix degeneration and synthesis. ${ }^{11}$ Strenuous physical exercise can lead to excessive tendon loading and therefore, is considered as the main pathological stimulus for degeneration. ${ }^{13}$

Excessive microstrain or 'overuse' on the tenocytes has been shown to induce the expression of several inflammatory mediators and matrix metalloproteinases (MMPs), which might trigger increased proteolytic activity in the tendon. ${ }^{14}$ However, the exact pathogenesis of tendinopathy is still not known. The current theory for tendinopathy is the continuum model, as presented by Cook and Purdam. ${ }^{15}$ Under the continuum model, tendinopathy is viewed as a spectrum ranging from normal tendon to pathologic tendon. The three stages included in the continuum model are: reactive tendinopathy, tendon dysrepair and degenerative tendinopathy.

In reactive tendinopathy, there is a proliferative cell response in the cell and tendon matrix which is noninflammatory in nature. This can occur after a sudden increase in stress or direct impact to the tendon. Due to the changes in proteoglycans, the tendon, on imaging, appear to be thickened and swollen. However, this phase is reversible and can be achieved with reduced tendon loading or sufficient rest. The tendon disrepair is next progressive stage where there is an attempt at tendon healing similar to reactive tendinopathy but with greater matrix involvement and breakdown. Some reversibility is possible with load management. Degenerative tendinopathy is the final stage of the continuum and is characterized by neovascularization, cell death, apoptosis and extensive matrix breakdown due to chronic overloading. The changes at this stage lead to poor tendon prognosis and have little to no capacity to revert to normal tendon. ${ }^{19}$

\section{CURRENT TREATMENT OPTIONS FOR TENDINOPATHY}

Various management options are available which include rest, ice, eccentric exercise, nutraceuticals, ultrasound therapy, sclerosing injections, extracorporeal shockwave therapy, splinting, taping, cryotherapy, electrotherapy, glyceryl trinitrate patches, NSAIDs as well as peritendinous injections. Surgery is often considered a last option in the treatment of tendinopathy that persists after exhausting all non-operative options. However, conservative measures remain the mainstay of treatment for most tendinopathies. ${ }^{5}$

\section{Eccentric exercise}

This form of exercise involves lengthening of muscle and tendon under tension. Its mechanism is not completely 
understood at the molecular level; however, it results in the production of new type I collagen and increase the density of collagen fibrils. ${ }^{16}$ They also promote collagen fibre cross-link formation within the tendon and facilitate tendon remodelling. ${ }^{17}$

\section{NSAIDs}

Prostaglandins are chemical molecules derived from arachidonic acid playing an important role in the development of acute inflammation. Both the oral and topical delivery of NSAIDs is effective as short-term analgesics for this painful condition. ${ }^{18}$

\section{Corticosteroids}

These are potent anti-inflammatory molecules. Despite the fact of little to no role of inflammatory process in the pathogenesis of tendinopathy, numerous studies have demonstrated corticosteroid therapy significantly improving the patient outcome in the short term by providing pain relief and enhancing function. ${ }^{19}$

\section{Platelet-rich plasma (PRP)}

Platelets play an important role in the healing of various injuries, as they are enriched with multiple growth factors and cytokines, including transforming growth factor beta (TGF- $\beta$ ), interleukins (ILs), fibroblast growth factors
(FGFs), platelet-derived growth factors (PDGFs), vascular endothelial growth factors (VEGFs), connective tissue growth factor (CTGF) and others. Various clinical studies have demonstrated mixed results regarding the effectiveness of PRP in treating patients with tendinopathy. ${ }^{20}$

\section{NUTRACEUTICALS}

The management of tendon injuries with oral nutritional supplements is relatively new. Numerous pre-clinical and clinical studies have been conducted to assess the effectiveness of oral supplements for the management of tendinopathies. The management of tendinopathies with oral supplements such as glucosamine and chondroitin sulfate, vitamin $\mathrm{C}$, hydrolyzed type 1 collagen, curcumin, boswellic acid and methylsulfonylmethane have potential role in tendon healing (Table 1). Current clinical studies often test combination of substances and compare the results of medication to physical activity interventions or other treatments.As many nutrients are required for the normal tendon health, nutritional supplements involving multiple nutrients would be more effective than the ones containing single ingredient. One dietary supplement composed of mucopolysaccharides, type 1 collagen, and vitamin $\mathrm{C}$ has been tested to manage different tendinopathies (Achilles, patellar and common extensor tendons). The overall results suggest improvement of symptoms and healing of injured tendons.

Table 1: Effects of nutritional supplement on the tendon.

\begin{tabular}{|c|c|}
\hline Nutritional supplement & Effect on the tendon \\
\hline Vitamin C & $\begin{array}{ll}\text { - } & \text { Has anti-inflammatory and antioxidant effect } \\
\text { - } & \text { Stimulates hydroxyproline synthesis of procollagen } \\
\text { - } & \text { Increases angiogenesis and maturation of col III to col I fibres }\end{array}$ \\
\hline Boswellic acid & $\begin{array}{ll}\text { - } & \text { Inhibits 5-lipooxygenase } \\
\text { - } & \text { Decreases the levels of TNF } \alpha, \text { IL-1, IL-2, IL-4, IL- } 6\end{array}$ \\
\hline Type I collagen & - Increases mechanical strength \\
\hline Curcumin & $\begin{array}{ll}- & \text { Has antioxidant effect } \\
- & \text { Inhibition of apoptosis } \\
- & \text { Enhances survival of tenocytes }\end{array}$ \\
\hline Methylsulfonylmethane (MSM) & $\begin{array}{ll}\text { - } & \text { Has analgesic properties } \\
\text { - } & \text { Also has anti-inflammatory and antioxidant effects }\end{array}$ \\
\hline Glucosamine and chondroitin sulphate & $\begin{array}{ll}\text { - } & \text { Increases synthesis of collagen } \\
\text { - } & \text { Enhances mechanical properties and organization of collagen bundles }\end{array}$ \\
\hline
\end{tabular}

\section{Surgery}

Surgical intervention is usually recommended if the results of medical management are unsatisfactory. Operative management should therefore be preferred in patients who have failed 3 to 6 months of conservative management. ${ }^{21}$

\section{LIMITATIONS OF THE CURRENT TREATMENT OPTIONS}

The major issue with traditional therapeutic strategies is that most of them are based on targeting inflammation only; they do not correct the structural abnormality in the tendon. Steroid injections are helpful in the short term (first approximately 4 weeks) however, their long-term effectiveness is not known, and quality of evidence for its use remains poor and controversial. ${ }^{22}$ According to the available scientific evidence, NSAIDs seems unlikely to be effective due to absence of inflammatory process in chronic tendinopathy. Also, very few clinical trials are available regarding the effectiveness of these interventions. Recently a nutritional supplement containing combination of type I collagen, vitamin $\mathrm{C}$ and mucopolysaccharides has demonstrated reduction in the 
clinical symptoms and has also improved structural evolution of different types of tendinopathies in clinical studies.

\section{ROLE OF NUTRACEUTICALS COMBINING TYPE I COLAGEN, MUCOPOLYSACCHARIDES AND VITAMIN C}

\section{Type I collagen}

Collagen forms the major extracellular protein in tendons, muscle, and ligaments. ${ }^{15,23}$ Therefore dietary supplements containing type I collagen would increase collagen synthesis which may be helpful in rebuilding tendons. Effects of ingestion of collagen peptide on rabbit's tendon extracellular matrix demonstrate that hydrolyzed type I collagen peptides not only affect the size of collagen fibrils but also the composition of glycosaminoglycans in Achilles tendon. The ingestion of type I collagen increased the amount of dermatan sulfate and lowered the percentage of hyaluronic acid. The rise of this biochemical component enhances the mechanical properties of Achilles tendon.

\section{Mucopolysaccharides}

In the tendons or ligaments, collagen mainly contributes to strength and structure, whereas mucopolysaccharides which are also known as glycosaminoglycans (GAGs) tend to provide "glue" effect which holds the fibers together and also allowing them the flexibility, stretching and bending properties as well as resilience. They are also one of the essential components of extracellular matrix. In one of the in-vitro studies, it was found that they also increase collagen and non-collagenous protein synthesis in cultures of bovine tenocytes and ligament cells. ${ }^{24}$

\section{Vitamin C}

The presence of vitamin $\mathrm{C}$ is necessary for the enzymatic synthesis of both collagen proteins and several proteoglycans found in tendons. ${ }^{25}$ Vitamin $\mathrm{C}$ is also a transcriptional promoter of collagen synthesis. A recent animal study reported that high dose oral vitamin $\mathrm{C}$ supplementation significantly accelerates the healing of ruptured Achilles tendons. ${ }^{26}$ The current in-vitro research data shows that tenocytes cultured in a medium without the presence of vitamin $\mathrm{C}$ synthesized collagen at only a third of the normal level. ${ }^{27}$

\section{EVIDENCE OF TYPE I COLLAGEN, MUCOPOLYSACCHARIDES AND VITAMIN C IN TENDINOPATHY}

\section{Preclinical evidence}

In one of the studies on an in-vitro model of tendon inflammation, the combination of type $\mathrm{I}$ collagen + mucopolysaccharides + vitamin $\mathrm{C}(\mathrm{C}+\mathrm{M}+\mathrm{V})$ suppressed IL- $1 \beta$-induced NF-k $\beta$ activation. These events lead to down-regulation of cyclooxygenase-2 (COX-2), matrix metalloproteinase-1 (MMP-1) and activated caspase-3. These results indicate the potential benefit of this combination as an anti-inflammatory agent for the treatment of tendinopathy. ${ }^{28}$ An experimental study was performed in Wistar Albino rats to evaluate the role of vitamin $\mathrm{C}$ for collagen synthesis in healing of Achilles tendon rupture. It demonstrated significantly higher mean collagen fibre diameter $(\mathrm{p}<0.001)$ and number of active fibroblasts as well as more noticeable type I collagen production $(\mathrm{p}=0.021)$ in vitamin $\mathrm{C}$ group. Also process of angiogenesis was more evident in vitamin $\mathrm{C}$ group as compared to control group. ${ }^{29}$ Also another preclinical study was performed in rats with aim to evaluate the effects of ascorbic acid (vitamin $\mathrm{C}$ ) on the periodontal ligament during aging. It showed that vitamin $\mathrm{C}$ supplementation promoted the maturation of collagen fibres and enhanced angiogenesis in the ligament. ${ }^{30}$

\section{Clinical evidence}

A randomized, controlled, multicentre trial was conducted in a total number of 59 patients with Achilles tendinopathy. The study groups consisted of combination of eccentric training (EC) or passive stretching (PS) along with nutritional supplement containing $\mathrm{C}+\mathrm{M}+\mathrm{V}$. Patients were diagnosed based on clinical examination which showed painful thickening of the Achilles tendon, and confirmed by ultrasonography (USG) which involved local thickening of the tendon, irregular tendon structure with hypoechoic areas and irregular fibre orientation. Patients who already received a previous treatment with eccentric training were excluded. Patients were divided into reactive tendinopathy and degenerative tendinopathy based on the Cook and Purdam pathology model. The study was approved by ethics committee. Patients in the EC plus $\mathrm{C}+\mathrm{M}+\mathrm{V}$ group consumed 3 capsules per day containing $435 \mathrm{mg}$ mucopolysaccharides, $75 \mathrm{mg}$ collagen type I and $60 \mathrm{mg}$ vitamin C. Patients in the PS plus $\mathrm{C}+\mathrm{M}+\mathrm{V}$ group consumed the nutraceutical and were advised to conduct passive stretching that was supervised weekly by a physiotherapist. At 6 and 12 weeks, a significant improvement in Victorian Institute of Sports Assessment-Achilles questionnaire (VISA-A) score as well as pain at rest and pain during activity were found in all treatment groups. ${ }^{31}$

Another randomized, placebo-controlled trial was performed in sixty patients with tendinopathy of Achilles, supraspinatus, lateral epicondyle or plantar fasciitis. One group received nutritional supplement containing $\mathrm{C}+\mathrm{M}+\mathrm{V}$ whereas other group received placebo for a period of 90 days. During the study, patients were followed up at monthly intervals. Pain intensity was measured using a visual analog scale (VAS). Ultrasound was used to characterize tendon structure as well as presence or absence of tendinopathy. The percentage of patients with clinical symptom progressively decreased in both groups, reaching lower values in the $\mathrm{C}+\mathrm{M}+\mathrm{V}$ group at each time period. Pain levels measured by VAS reduced significantly in both the groups; however, patients receiving nutritional 
supplement had significantly lower pain value at 90 days ( $\mathrm{p}<0.05)$. Also patients who received $\mathrm{C}+\mathrm{M}+\mathrm{V}$ had more improvement in clinical symptoms as compared to placebo. Interestingly, patients in the $\mathrm{C}+\mathrm{M}+\mathrm{V}$ group were free of tendinopathy at the end of the study according to ultrasound assessment. ${ }^{32}$

In other multicenter, open-label, non-comparative, prospective, exploratory phase IV trial, a total of 98 patients were recruited with tendinopathies of the Achilles tendon (AC group), patellar tendon (PA group) and lateral epicondyle tendon in the elbow (LE group). The diagnosis of tendinopathy was based upon a clinical examination which involved swelling of the tendon that was painful upon palpation, and it was confirmed by ultrasound as local swelling of the tendon, an irregular structure with hypoechoic regions and irregular orientation of the fibers. All the patients in the study were provided 3 capsules of $\mathrm{C}+\mathrm{M}+\mathrm{V}$ per day for 90 consecutive days. They were followed up at monthly intervals. Pain levels at rest and when active as well as different scales for joint function improvement such as VISA-A, VISA-P (Victorian Institute of Sports Assessment- Patellar tendon questionnaire (VISA-P) and PRTEE (Patient-rated tennis elbow evaluation) were measured each month. Pain intensity levels at rest and when active was measured by a 10-centimetre VAS. A significant reduction in the pain was found both rest and when active in all three groups. It was progressive throughout the study, and was significant at the first control visit performed on day 30 of treatment $(\mathrm{p}<0.01)$.

The intensity of the pain at rest decreased by $80 \%$ for the AC group, $71 \%$ for the PA group and $91 \%$ for the LE group at the end of the study (day 90) as compared to the baseline pain levels $(\mathrm{p}<0.001)$. Also pain while moving decreased by $82 \%$ for the AC group, $73 \%$ for the PA group and $81 \%$ for the LE group ( $\mathrm{p}<0.001)$. At day 30 and 90 , a significant reduction in pain both at rest and when active was observed in all the groups. There was $38 \%$ improvement in VISA-A, $46 \%$ in VISA-P and $77 \%$ in PRTEE scores at day $90(\mathrm{p}<0.001)$. A significant reduction in the thickness of the affected tendon was found in all the treatment groups. It was $12 \%$ decrease in the thickness of Achilles tendon, a $10 \%$ decrease in the patellar tendon and a $20 \%$ decrease in lateral epicondyle tendon was found $(\mathrm{p}<0.05)$. Also, NSAID drug consumption was reduced significantly during the study period. This reduction was $5 \%$ as compared to $28 \%$ which was 30 days prior to the baseline visit in the AC group whereas in the PA group it reduced to $14 \%$ from $43 \%$ ( $<<0.05) .{ }^{33}$

In another observational study, a total of 80 participants were recruited of epicondylitis, supraspinous tendinopathy, Achilles tendinopathy and plantar fasciitis. In each group of the clinical condition comprising 20 patients, there were a study group and a control group. The total duration of the study was of 3 months. The study group received $\mathrm{C}+\mathrm{M}+\mathrm{V}$. Pain, SF36 quality of life survey and standardized functional assessments were evaluated pre and 1, 2 and 3 months post-treatment. There was significant reduction in pain $(\mathrm{p}<0.05)$ in all the subgroups except for the epicondylitis group. Improvement of at least one SF36 subscale along with pain reduction was found in each subgroup $(p<0.05)$. At the end of the treatment, there was a significant improvement in the functional assessment of the physiotherapist in all the treatment groups $(\mathrm{p}<0.05){ }^{34}$

Table 2: Clinical evidence for Type I collagen $(C)+$ mucopolysaccharides $(M)+$ vitamin $C(V)$ in tendinopathy.

\begin{tabular}{|c|c|c|c|c|}
\hline $\begin{array}{l}\text { Authors } \\
\text { (year) }\end{array}$ & Study design & Subjects & $\mathbf{N}$ & Outcome \\
\hline $\begin{array}{l}\text { Balius et } \\
\text { al }(\mathbf{2 0 1 6})^{31}\end{array}$ & $\begin{array}{l}\text { Randomized, controlled, } \\
\text { multicentre trial }\end{array}$ & $\begin{array}{l}\text { Patients with Achilles } \\
\text { tendinopathy }\end{array}$ & 59 & $\begin{array}{l}\text { A significant improvement in Victorian } \\
\text { Institute of Sports Assessment-Achilles } \\
\text { questionnaire score, pain at rest, and pain } \\
\text { during activity were detected in all } 3 \\
\text { treatment groups at } 6 \text { and } 12 \text { weeks' } \\
\text { follow-up when compared with baseline. }\end{array}$ \\
\hline $\begin{array}{l}\text { Binh et al } \\
(2014)^{32}\end{array}$ & $\begin{array}{l}\text { Randomized, placebo- } \\
\text { controlled study }\end{array}$ & $\begin{array}{l}\text { Patients with tendinopathy } \\
\text { of Achilles, supraspinatus, } \\
\text { lateral epicondyle or } \\
\text { plantar fasciitis }\end{array}$ & 60 & $\begin{array}{l}\text { Visual Analogue Scale (VAS) was } \\
\text { significantly reduced in patients } \\
\text { supplemented with } \mathrm{C}+\mathrm{M}+\mathrm{V} \text { at } 90 \text { days }\end{array}$ \\
\hline $\begin{array}{l}\text { Martinez } \\
\text { et al } \\
(\mathbf{2 0 1 4})^{\mathbf{3 4}}\end{array}$ & $\begin{array}{l}\text { Multicenter, open-label, } \\
\text { non-comparative, } \\
\text { prospective, exploratory } \\
\text { phase IV study }\end{array}$ & $\begin{array}{l}\text { Patients with } \\
\text { tendinopathies of Achilles } \\
\text { tendon, patellar tendon and } \\
\text { lateral epicondyle tendon } \\
\text { in the elbow }\end{array}$ & 98 & $\begin{array}{l}\text { A significant reduction in pain both at rest } \\
\text { and when active was observed between } \\
\text { day } 30 \text { and the end of the study (day 90) } \\
\text { for all three types of tendinopathy. A } 38 \% \\
\text { improvement in VISA-A, } 46 \% \text { in VISA-P } \\
\text { and } 77 \% \text { in PRTEE was observed on day } \\
90(\mathrm{p}<0.001) \text {. }\end{array}$ \\
\hline $\begin{array}{l}\text { Nadal et } \\
\text { al }(2009)^{34}\end{array}$ & $\begin{array}{l}\text { Prospective } \\
\text { observational study }\end{array}$ & $\begin{array}{l}\text { Patients with epicondylitis, } \\
\text { supraspinatus tendonitis, } \\
\text { Achilles tendonitis and } \\
\text { plantar fasciitis }\end{array}$ & 80 & $\begin{array}{l}\text { The study group displayed a significant } \\
\text { pain reduction }(\mathrm{p}<0.05) \text { in all the } \\
\text { subgroups except for the epicondylitis } \\
\text { group. }\end{array}$ \\
\hline
\end{tabular}




\section{CONCLUSION}

Tendinopathy is a common disorder which continues to be very difficult to manage because of its recurrent nature and a definitive treatment is still not available. Nutraceuticals emerge as candidates to reduce symptoms attributed to tendinopathies, prevent tendon rupture, and improve recovery from trauma or surgery. Nutraceutical supplements such as combination of type I collagen, mucopolysaccharides and vitamin $\mathrm{C}$ not only reduce the clinical symptoms but also improve structural evolution of different types of tendinopathies as well as plantar fascitis. Clinical data suggests that this formulation promotes the endogenous synthesis of collagen type I, avoiding the accumulation of collagen type III and aggrecan, thus interfering with the degeneration of tendon tissue. The combination of type I collagen, mucopolysaccharides and vitamin $\mathrm{C}$ is safe and effective for management of different tendinopathies, providing an additional benefit to eccentric training, especially at early stages of the disease.

Funding: No funding sources

Conflict of interest: None declared

Ethical approval: Not required

\section{REFERENCES}

1. Dean BJF, Dakin SG, Millar NL, Carr AJ. Review: emerging concepts in the pathogenesis of tendinopathy. Surgeon. 2017;15(6):349-54

2. Wilson JJ, Best TM. Common overuse tendon problems: a review and recommendations for treatment. Am Fam Phys. 2005;72(5):811-8.

3. Littlewood C, May S, Walters S. Epidemiology of rotator cuff tendinopathy: a systematic review. Shoulder Elb. 2013;5(4):256-65.

4. Tilley BJ, Cook JL, Docking SI, Gaida JE. Is higher serum cholesterol associated with altered tendon structure or tendon pain? A systematic review. Br J Sports Med. 2015;49(23):1504-9.

5. Andres, BM, Murrell GAC. Treatment of tendinopathy: what works, what does not, and what is on the horizon. Clin Orthop Rel Res. 2008;466(7):1539-54.

6. Best TM, Garrett WE. Basic science of soft tissue: muscle and tendon. In: DeLee JC, Drez D Jr, editors. Orthopaedic sports medicine: principles and practice. Philadelphia: WB Saunders. 1994;1.

7. Oxlund H. Relationships between the biomechanical properties, composition and molecular structure of connective tissues. Connect Tissue Res. 1986;15:6572.

8. Kannus P, Jozsa L, Jarvinnen M. Basic science of tendons. In: Garrett WE Jr, Speer KP, Kirkendall DT, editors. Principles and practice of orthopaedic sports medicine. Philadelphia: Lippincott Williams and Wilkins. 2000;21-37.

9. Docheva D, Muller SA, Majewski M, Evans $\mathrm{CH}$ : Biologics for tendon repair. Adv Drug Deliv Rev. 2015;84:222-39.
10. Dyment NA, Galloway JL: Regenerative biology of tendon: mechanisms for renewal and repair. Curr Mol Biol Rep. 2015;1(3):124-31.

11. Kvist M, Jozsa L, Jarvinen M, Kvist H. Fine structural alterations in chronic Achilles paratenonitis in athletes. Pathol Res Pract. 1985; 180:416-23.

12. Williams JG. Achilles tendon lesions in sport. Sports Med. 1986;3:114-35.

13. Selvanetti A, Cipolla M, Puddu G. Overuse tendon injuries: basic science and classification. Oper Tech Sports Med. 1997;5:110-7.

14. Archambault J, Tsuzaki M, Herzog W, Banes AJ. Stretch and interleukin-1 beta induce matrix metalloproteinases in rabbit tendon cells in vitro. $\mathbf{J}$ Orthop Res. 2002;20:36-9.

15. Cook JL, Rio E, Purdam CR, Docking SI. Re-visiting the continuum model of tendon pathology: what is its merit in clinical practice and research? Br J Sports Med. 2016;50:1187-91.

16. Langberg H, Ellingsgaard H, Madsen T, Jansson J, Magnusson SP, Aagaard P, Kjaer M. Eccentric rehabilitation exercise increases peritendinous type I collagen synthesis in humans with Achilles tendinosis. Scand J Med Sci Sports. 2007;17:61-6.

17. Maffulli N, Longo UG. How do eccentric exercises work in tendinopathy?. Rheumatol (Oxford). 2008;47(10):1444-5.

18. Petri M, Hufman SL, Waser G, Cui H, Snabes MC, Verburg KM. Celecoxib effectively treats patients with acute shoulder tendinitis/bursitis. J Rheumatol. 2004;31:1614-20.

19. Smidt N, Assendelft WJ, van der Windt DA, Hay EM, Buchbinder R, Bouter LM. Corticosteroid injections for lateral epicondylitis: a systematic review. Pain. 2002;96:23-40.

20. Kia C, Baldino J, Bell R, Ramji A, Uyeki C, Mazzocca A. Platelet-rich plasma: review of current literature on its use for tendon and ligament pathology. Curr Rev Musculoskeletal Med. 2018;11(4):566-72.

21. Khan KM, Cook JL, Maffulli N, Kannus P. Where is the pain coming from in tendinopathy? It may be biochemical, not only structural, in origin. Br J Sports Med. 2000;34:81-3.

22. Coombes BK, Bisset L, Vicenzino B. Efficacy and safety of corticosteroid injections and other injections for management of tendinopathy: a systematic review of randomised controlled trials: The Lancet. 2010;376(9754):1751-67.

23. Docheva D, Muller SA, Majewski M, Evans CH: Biologics for tendon repair. Adv Drug Deliv Rev. 2015;84:222-39.

24. Lippiello L. Collagen synthesis in tenocytes, ligament cells and chondrocytes exposed to a combination of glucosamine $\mathrm{HCl}$ and chondroitin sulfate. Evid Based Complement Alternat Med. 2007;4(2):219-24.

25. Berg RA, Kerr JS. Nutritional aspects of collagen metabolism. Annu Rev Nutr. 1992;12:369-90. 
26. Omeroglu S, Peker T, Turkozkan N, Omeroglu H. High-dose vitamin $\mathrm{C}$ supplementation accelerates the Achilles tendon healing in healthy rats. Arch Orthop Trauma Surg. 2009;129(2):281-6.

27. Kao WW, Flaks JG, Prockop DJ. Primary and secondary effects of ascorbate on procollagen synthesis and protein synthesis by primary cultures of tendon fibroblasts. Arch Biochem Biophys. 1976;173:638-48.

28. Shakibaei M, Buhrmann C, Mobasheri A. Antiinflammatory and anti-catabolic effects of TENDOACTIVE® on human tenocytes in vitro. Histol Histopathol Cell Mol Biol. 2011;26(9):117385.

29. Omeroğlu S, Peker T, Türközkan N, Omeroğlu H. High-dose vitamin $\mathrm{C}$ supplementation accelerates the Achilles tendon healing in healthy rats. Arch Orthop Trauma Surg. 2009;129(2):281-6.

30. Zanoni JN, Lucas NM, Trevizan AR, Souza ID. Histological evaluation of the periodontal ligament from aged Wistar rats supplemented with ascorbic acid. An Acad Bras Cienc. 2013;85(1):327-35.

31. Balius R, Álvarez G, Baró F, Jiménez F, Pedret C, Costa E, Martínez-Puig D. A 3-arm randomized trial for achilles tendinopathy: eccentric training, eccentric training plus a dietary supplement containing mucopolysaccharides, or passive stretching plus a dietary supplement containing mucopolysaccharides. Curr Therap Res. 2016;78,17.

32. Binh BH, Ramirez P, Martinez-Puig D. THU0338: A randomized, placebo-controlled study to evaluate efficacy and safety of a dietary supplement containing mucopolysaccharides, collagen type $i$ and vitamin $\mathrm{c}$ for management of different tendinopathies. Ann Rheum Dis. 2016;73(2):299301.

33. Arquer A, Garcia M, Laucirica JA, Riusd M, Blàviae $\mathrm{M}$, Fontserè $\mathrm{J}$, et al. The efficacy and safety of oral mucopolysaccharide, type I collagen and vitamin C treatment in tendinopathy patients. Apunts Med Esport. 2014;49(182):31-6.

34. Nadal F, Bové T, Sanchís D, Martinez-Puig D. 473 Effectiveness of treatment of tendinitis and plantar fasciitis by tendoactive ${ }^{\mathrm{TM}}$. Osteoarthritis Cartilage. 2009; 17:253.

Cite this article as: Agrawal D, Shah A, Mehta $\mathrm{KD}$, Jain R, Motlekar S. Role of nutritional supplements in the management of tendinopathies: focus on combination of type 1 collagen, vitamin $\mathrm{C}$ and mucopolysaccharides. Int J Res Orthop 2020;6:1355-61. 